\title{
Characterization of outcomes I year after endoscopic thermal vapor ablation for patients with heterogeneous emphysema
}

This article was published in the following Dove Press journal:

International Journal of COPD

3 July 2012

Number of times this article has been viewed

\author{
Felix JF Herth' \\ Armin Ernst ${ }^{2}$ \\ Kimberly M Baker ${ }^{3}$ \\ Jim J Egan ${ }^{4}$ \\ Mark H Gotfried ${ }^{5}$ \\ Peter Hopkins ${ }^{6}$ \\ Franz Stanzel $^{7}$ \\ Arschang Valipour ${ }^{8}$ \\ Manfred Wagner ${ }^{9}$ \\ Christian Witt ${ }^{10}$ \\ Steven Kesten"1 \\ Gregory Snell ${ }^{12}$
}

'Pneumology and Critical Care Medicine, Thoraxklinik Heidelberg, Heidelberg,

Germany; ${ }^{2}$ St Elizabeth's Medical Center, Boston, MA, USA; ${ }^{3}$ University of lowa,

lowa City, IA, USA; ${ }^{4}$ Advanced Lung

Disease Program, Mater Misericordiae

University Hospital, Dublin, Ireland;

${ }^{5}$ Pulmonary Associates, Phoenix, AZ,

USA; 'ung Transplant Unit, Prince

Charles Hospital, Chermside, Australia;

${ }^{7}$ Zentrum für Pneumologie, Hemer,

Germany; ${ }^{8}$ Ludwig-Boltzmann-Institute

for COPD, Otto-Wagner-Hospital,

Vienna, Austria; ${ }^{9}$ Klinikum Nürnberg,

Nürnberg, Germany; ${ }^{10}$ Pneumology,

Charité Campus-Mitte, Berlin, Germany;

"Uptake Medical Corp, Tustin, CA, USA;

${ }^{12}$ Allergy Immunology and Respiratory

Medicine, The Alfred Hospital,

Melbourne, Australia

Correspondence: Felix JF Herth Department of Pneumology and Critical Care Medicine, Thoraxklinik, Member of the German Center for Lung

Research, University of Heidelberg,

Amalienstrasse 5, DE-69I26 Heidelberg.

Germany

Tel $+49622 I 396$ I200

Fax $+496221396 \quad 1202$

Email felix.herth@thoraxklinik-

heidelberg.de
Introduction: Endoscopic lung volume reduction has been developed as a therapeutic option for advanced emphysema. Six-month results following treatment with endoscopic thermal vapor ablation (InterVapor ${ }^{\mathrm{TM}}$; Uptake Medical, Tustin, CA) were described previously, and here we report observations from the 12-month assessment.

Methods: Two multicenter, international, single-arm trials of InterVapor (unilateral upper lobe treatment) in patients with upper lobe predominant emphysema were conducted. Inclusion criteria: forced expiratory volume in 1 second $\left(\mathrm{FEV}_{1}\right) 15 \%-45 \%$ predicted, residual volume $>150 \%$, total lung capacity $>100 \%$, 6-minute walk distance $(6 \mathrm{MWD})>140 \mathrm{~m}$, and diffusing capacity for carbon monoxide $>20 \%$ predicted. Efficacy endpoints: spirometry, body plethysmography, lung volumes by high-resolution computed tomography, St George's Respiratory Questionnaire, modified Medical Research Council dyspnea scale, and 6MWD. All adverse events were collected and independently adjudicated.

Results: Forty four patients were treated at a mean (standard deviation) age of 63 (5.6) years, $\mathrm{FEV}_{1} 0.86 \mathrm{~mL}(0.25 \mathrm{~mL})(\mathrm{n}=22$ men and 22 women). Mean (standard deviation) changes from baseline at 12 months were: FEV $86.2 \mathrm{~mL}(173.8 \mathrm{~mL})$, St George's Respiratory Questionnaire -11.0 (14.0) units, treated lobar volume from high-resolution computed tomography $-751.8 \mathrm{~mL}(653.9 \mathrm{~mL})$, residual volume $-302.8 \mathrm{~mL}(775.6 \mathrm{~mL}), 6 \mathrm{MWD} 18.5 \mathrm{~m}$ $(63.7 \mathrm{~m})$, and modified Medical Research Council dyspnea scale score $-0.83(0.97)(P<0.05$ for all except 6MWD). Improvements were numerically larger at 6 versus 12 months. GOLD stage III and IV patients had similar outcomes at 6 months; however, improvements relative to baseline were numerically higher in GOLD stage IV patients. Larger improvements were observed in patients with higher heterogeneity. In total, 39 serious adverse events were reported in 23 patients with 10 events in 8 patients between 6 and 12 months.

Conclusion: Unilateral lobar InterVapor treatment of heterogeneous emphysema improved lung function and health outcomes 1 year following treatment. The magnitude of improvement was larger at 6 months compared to 12 months. Improvements relative to baseline continue to be exhibited at 12 months despite the expected disease related decline over time.

Clinical trials: NCT 01041586 and NCT 01102712

Keywords: emphysema, bronchoscopy, lung volume reduction, thermal energy

\section{Introduction}

Surgical removal of poorly functioning hyperinflated emphysematous lung results in long-term improvement in lung function, symptoms, exercise tolerance, and healthrelated quality of life in appropriately selected patients with emphysema. ${ }^{1-5}$ Selection is based on a phenotype of patients characterized by severe and very severe emphysema, predominantly upper lobe heterogeneous disease, and physiological variables indicating 
that the disease has not become end-stage., ${ }^{3,4}$ While lung volume reduction surgery is beneficial to such patients, surgical intervention is only performed in a small number of presumably eligible patients. ${ }^{6}$ In the United States, only 105 Medicare beneficiaries underwent lung volume reduction surgery in 2006. ${ }^{6}$ Although various reasons have been proposed for this discrepancy, one prominent factor may be the short-term morbidity and mortality of this disease. Therefore, minimally invasive endoscopic techniques have been developed that are designed to induce lung volume reduction. ${ }^{7-13}$

The critical issue for any endoscopic approach appears to be identifying patients and phenotypes that will achieve meaningful lung volume reduction based on the assumption that reduced lobar volume (removal of tissue, ablation, or collapse) is the basis for clinical improvement. However, it is acknowledged that other mechanisms may contribute. Data from insertion of intrabronchial valves have documented improvement in 6-minute walk distance (6MWD) and the St George's Respiratory Questionnaire (SGRQ) in the absence of improvement in forced expiratory volume in 1 second $\left(\mathrm{FEV}_{1}\right) \cdot{ }^{14}$ The authors hypothesized that redirection of airflow between lobes may be an alternative mechanism of action.

InterVapor $^{\mathrm{TM}}$ (Uptake Medical Corp., Tustin, CA) is a minimally invasive endoscopic technique in which thermal energy in the form of heated water vapor is directly administered to targeted regions of the lung. ${ }^{15-17}$ The thermal energy leads to a short-term inflammatory response that is followed by healing with contraction fibrosis and atelectasis distal to fibrosed airways and subsequent lobar volume reduction. ${ }^{15-17}$ A recently published single-arm clinical trial of InterVapor administered unilaterally in 44 patients with upper lobe predominant emphysema demonstrated significant lobar reduction, improved airflow, reduced hyperinflation, and improved health outcomes (dyspnea, exercise tolerance, and health-related quality of life) at 6 months. ${ }^{17}$ Follow-up data from a 12-month visit was obtained that permits documentation of longer term safety and efficacy as well as exploration of subgroup analyses that may identify groups of patients that have differential responses.

\section{Methods}

\section{Study design}

The methodology has been described previously. ${ }^{17}$ In brief, the data are based on two open-label, single-arm efficacy and safety clinical studies (clinical study protocols 0519
[NCT 01041586] and 0808 [NCT 01102712]) that evaluated unilateral InterVapor in the United States, Europe, and Australia. The clinical protocols have identical inclusion/ exclusion criteria, efficacy variables, and adverse event collection, with the key differences being additional clinic visits (at 3 weeks and 2 months) and no high-resolution computed tomography (HRCT) at 12 months in protocol 0519. This analysis is from pooled data without the aforementioned information. Following treatment with InterVapor, subjects were asked to return to the clinic at weeks 1, 2, and 4, and at months 3, 6, and 12. The protocol was approved by local institutional review boards or ethics committees and all patients provided written informed consent prior to participation.

\section{Study population}

The key inclusion criteria were: upper lobe predominant emphysema determined from HRCT, aged 40 to 75 years, $\mathrm{FEV}_{1}$ between $15 \%$ and $45 \%$ predicted, residual volume $(\mathrm{RV})>150 \%$ predicted, total lung capacity $>100 \%$, diffusing capacity for carbon monoxide $>20 \%$ predicted, $6 \mathrm{MWD}>140 \mathrm{~m}$, partial pressure of $\mathrm{CO}_{2}<55 \mathrm{mmHg}$ and partial pressure of $\mathrm{O}_{2}>45 \mathrm{mmHg}$, nonsmoking $\geq 4$ months, and recent participation in pulmonary rehabilitation. Key exclusion criteria were: known $\alpha$-1-antitrypsin deficiency, clinically significant asthma, chronic bronchitis or bronchiectasis, recent pneumothorax, bullae $>1 / 3$ of lobe, thoracotomy, left ventricular ejection fraction $\leq 40 \%$, and pulmonary hypertension (peak systolic pulmonary artery pressure $\geq 45 \mathrm{mmHg}$ or mean pulmonary artery pressure $\geq 35 \mathrm{mmHg}$ ).

\section{Procedure}

The InterVapor system delivers thermal energy to the airways of an upper lobe through the direct administration of heated water vapor. The system consists of a vapor generator, a catheter directed through a flexible bronchoscope, and a personalized procedure plan. The procedure plan was based on the calculated amount of energy (10 calories per gram of tissue) for each lung segment targeted for treatment. The amount of tissue was determined from software analysis (PW2 Software; VIDA Diagnostics Inc, Mountain View, CA) of a lung HRCT. Treatment time was between 3 and 10 seconds per airway treated. Selection of the lung targeted for treatment was based on the degree of heterogeneity and other anatomical factors. Further details of the procedure have been described previously. ${ }^{17}$ 


\section{Outcomes}

Efficacy measures assessed included lobar volume changes from HRCT, spirometry, body plethysmography, diffusing capacity for carbon monoxide, 6MWD, modified Medical Research Council dyspnea score, and the SGRQ. ${ }^{18-20}$ Primary endpoint testing was prespecified at 6 months with the 12-month data providing supportive information. The primary efficacy endpoint was the proportion of patients having an improvement from baseline in $\mathrm{FEV}_{1}>12 \%$ or in SGRQ total score $\geq 4$ units. The BODE (body mass index, obstruction, dyspnea, exercise) index was also calculated. ${ }^{21}$

All adverse events were reported throughout the trial with the primary diagnosis adjudicated by an independent physician.

\section{Analysis}

Descriptive statistics were performed for changes from baseline. Nominal $P$ values were determined from paired $t$-tests. No correction for multiple comparisons was performed. Frequencies and percentages were calculated for categorical variables. No imputation was used for missing data. Post-hoc subgroup analyses were performed based on GOLD stage and heterogeneity index (HI). Patients were dichotomized based on low and high $\mathrm{HI}$ based on the median value. HI was calculated as the ratio of lower to upper lobe tissue mass to air volume.

\section{Results}

Twenty-four patients received treatment to the right upper lobe and 20 received treatment to the left upper lobe. ${ }^{17}$ All procedures were completed successfully with no procedural complications. Data was not available for 4 patients at 6 months ( 2 missed visits, 1 withdrawn, 1 serious adverse event) and for 7 patients at 12 months (1 missed visit, 4 withdrawn, 2 serious adverse events).

\section{Demographics}

Fifty percent of patients were women, all were Caucasian, and the mean (standard deviation [SD]) age was 63.1 (5.6) years (Table 1). Lung function testing indicated GOLD stage III/IV disease and substantial gas trapping with hyperinflation. SGRQ and 6MWD were consistent with significant impairment. Fifteen patients (34.1\%) had a history of chronic obstructive pulmonary disease (COPD) exacerbations requiring hospitalization in the 12 months prior to the procedure. Of these 15 patients, 12 had one event,
Table I Baseline characteristics of 44 patients treated with InterVapor

\begin{tabular}{|c|c|}
\hline Age (years) & $63.1(5.6)$ \\
\hline Men (\%) & 50 \\
\hline Body mass index & $25.3(4.2)$ \\
\hline Duration of COPD diagnosis (years) & $7.3(4.4)$ \\
\hline Smoking history (pack-years) & $56.2(34.5)$ \\
\hline BODE score & $5.7(1.5)$ \\
\hline mMRC score & $2.9(0.7)$ \\
\hline 6MWD (m) & $299.9(77.0)$ \\
\hline SGRQ total score & $58.9(14.0)$ \\
\hline \multicolumn{2}{|l|}{ Pulmonary function } \\
\hline $\mathrm{FEV}_{1}(\mathrm{~mL})$ & $86 \mid(253)$ \\
\hline $\mathrm{FEV}_{1}$ (\% predicted) & $31.4(7.5)$ \\
\hline FVC (\% predicted) & $72.6(12.9)$ \\
\hline TLC (\% predicted) & $138.9(16.1)$ \\
\hline RV (\% predicted) & $237.0(50.1)$ \\
\hline DLCO (\% predicted) & $34.8(12.5)$ \\
\hline $\mathrm{PaO}_{2}(\mathrm{mmHg})$ & $68.9(12.1)$ \\
\hline $\mathrm{PaCO}_{2}(\mathrm{mmHg})$ & $39.4(7.2)$ \\
\hline $\mathrm{pH}$ & 7.43 \\
\hline \multicolumn{2}{|l|}{ Maintenance respiratory medications } \\
\hline Tiotropium & $95 \%$ \\
\hline Long-acting beta-agonists & $21 \%$ \\
\hline Inhaled steroids & $6 \%$ \\
\hline Long-acting beta-agonist + inhaled steroid & $70 \%$ \\
\hline Theophyllines & $23 \%$ \\
\hline Oral steroids & $16 \%$ \\
\hline Supplemental oxygen & $16 \%$ \\
\hline
\end{tabular}

Note: Values displayed as mean $\pm S D$ unless otherwise specified.

(c) 20 I2. European Respiratory Society. Reproduced with permission of the European Respiratory Society from Snell G, Herth FJ, Hopkins P, et al. Bronchoscopic thermal vapour ablation therapy in the management of heterogeneous emphysema. Eur Respir J. 2012;39(6):1328. ${ }^{17}$

Abbreviations: COPD, chronic obstructive pulmonary disease; BODE, body mass index, obstruction, dyspnea, exercise; mMRC, modified Medical Research Council dyspnea scale; 6MWD, 6-minute walk distance; SGRQ, St George's Respiratory Questionnaire; FEV, forced expiratory volume in I second; FVC, forced vital capacity; TLC, total lung capacity; RV, residual volume; $\mathrm{DLCO}$, diffusing capacity for carbon monoxide; $\mathrm{PaO}_{2}$, partial pressure of oxygen; $\mathrm{PaCO}_{2}$, partial pressure of carbon dioxide.

one patient had two events, and two patients had three events. Maintenance respiratory medication use was consistent with treatment guidelines. ${ }^{22}$

\section{Efficacy}

The primary endpoint was achieved in $84 \%$ of evaluable patients at 6 months with $78 \%$ of patients reaching the same endpoint at 12 months.

\section{Physiologic}

Significant reductions in upper lobar volume and increases in lower lobar volume were observed at 6 and 12 months $(P<0.001)$. Evaluable HRCT scans at 12 months were not available in 16 patients (10 excluded from protocol 0519 , four withdrawn, one missed visit, and one serious adverse event). Data for those patients having both 6- and 12-month 
HRCTs $(n=27)$ are presented in Figure 1, which indicates that lobar volume changes were stable.

The mean (SD) improvement in $\mathrm{FEV}_{1}$ was $141 \mathrm{~mL}$ $(166 \mathrm{~mL} ; 17 \%)$ and $86 \mathrm{~mL}(174 \mathrm{~mL} ; 10 \%)$ at 6- and 12 -months, respectively $(P<0.001$; Figure 2$)$. At 6 months, 23 subjects (58\%) had improvements $\geq 100 \mathrm{~mL}_{\text {in }} \mathrm{FEV}_{1}$ with 22 subjects ( $55 \%$ of evaluable patients) having an increase $\geq 12 \%$, and $20(50 \%)$ having an increase $\geq 15 \%$. At 12 months, 18 sub-

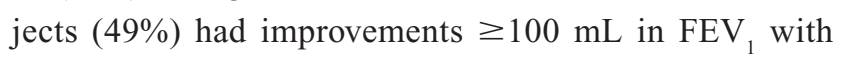
17 subjects (46\%) having an increase $\geq 12 \%$, and $15(41 \%)$ having an increase $\geq 15 \%$. The mean (SD) improvement in $\mathrm{RV}$ was $-406 \mathrm{~mL}$ (714 mL; 8\%) and -303 mL (776 mL; 6\%) at 6 and 12 months, respectively $(P<0.001$; Figure 3$)$. The pulmonary function results are displayed in Table 2.

\section{Health-related quality of life}

Significant improvements were demonstrated in the SGRQ total score with a change of -14 units at 6 months and -11 units at 12 months (Table 3 ). The total score improved by the minimal clinically important difference of four units ${ }^{19}$ in 29 evaluable subjects $(72.5 \%)$ at 6 months and 25 subjects $(67.6 \%)$ at 12 months $(P<0.001)$.

\section{Dyspnea, exercise, and BODE score}

At 6 and 12 months, the mean (SD) improvement in 6MWD was $46.5 \mathrm{~m}(67.1 \mathrm{~m})$ and $18.5 \mathrm{~m}(63.7 \mathrm{~m})$, respectively $(P<0.001$ at 6 months). The corresponding improvements (ie, reductions) in the modified Medical Research Council score were $0.90(1.06)$ and $0.83(0.97)$ units $(P<0.001)$. Twenty-five subjects (63\%) reported an improvement of $\geq 1$ unit at 6 months and $21(58.3 \%)$ at 12 months, compared to baseline.

The mean (SD) improvement in the BODE index was $1.48(1.75)$ and 1.25 (1.75) units at 6 and 12 months, respectively $(P<0.001)$. At 6 months after InterVapor treatment, $28(70 \%)$ of the subjects had a decrease in BODE index, six $(15 \%)$ had no change, and six $(15 \%)$ had deteoriated. Corresponding 12 month values were 22 (61\%), 8 (22\%), and $6(17 \%)$ units.

\section{Subgroup analyses}

Post-hoc subgroup analyses were performed based on GOLD stage III and GOLD stage IV disease severity and for patients based on HI (above and below median value of 1.6).

For GOLD stage, there were equal numbers of women in each group (11 each) with the mean age being similar. $\mathrm{FEV}_{1}$ (\% predicted) was 36.3\% (4.9\%) versus $26.5 \%(6.3 \%)$ with RV (\% predicted) being 233\% (46.4\%) and 241\% (54.4\%) in GOLD stage III and IV groups, respectively. Mean HI was similar. Efficacy was observed at 6 and 12 months in both subgroups with findings similar at 6 months (Table 4). Twelve month efficacy was numerically higher in GOLD stage IV patients ( $P>0.05$ for comparisons between GOLD stages).

For HI, there were 9 and 13 women in the $<1.6$ and $>1.6$ groups with the mean age being similar. $\mathrm{FEV}_{1}$ (\% predicted) was $30.6 \%(7.3 \%)$ versus $32.1 \%$ (7.8\%) with
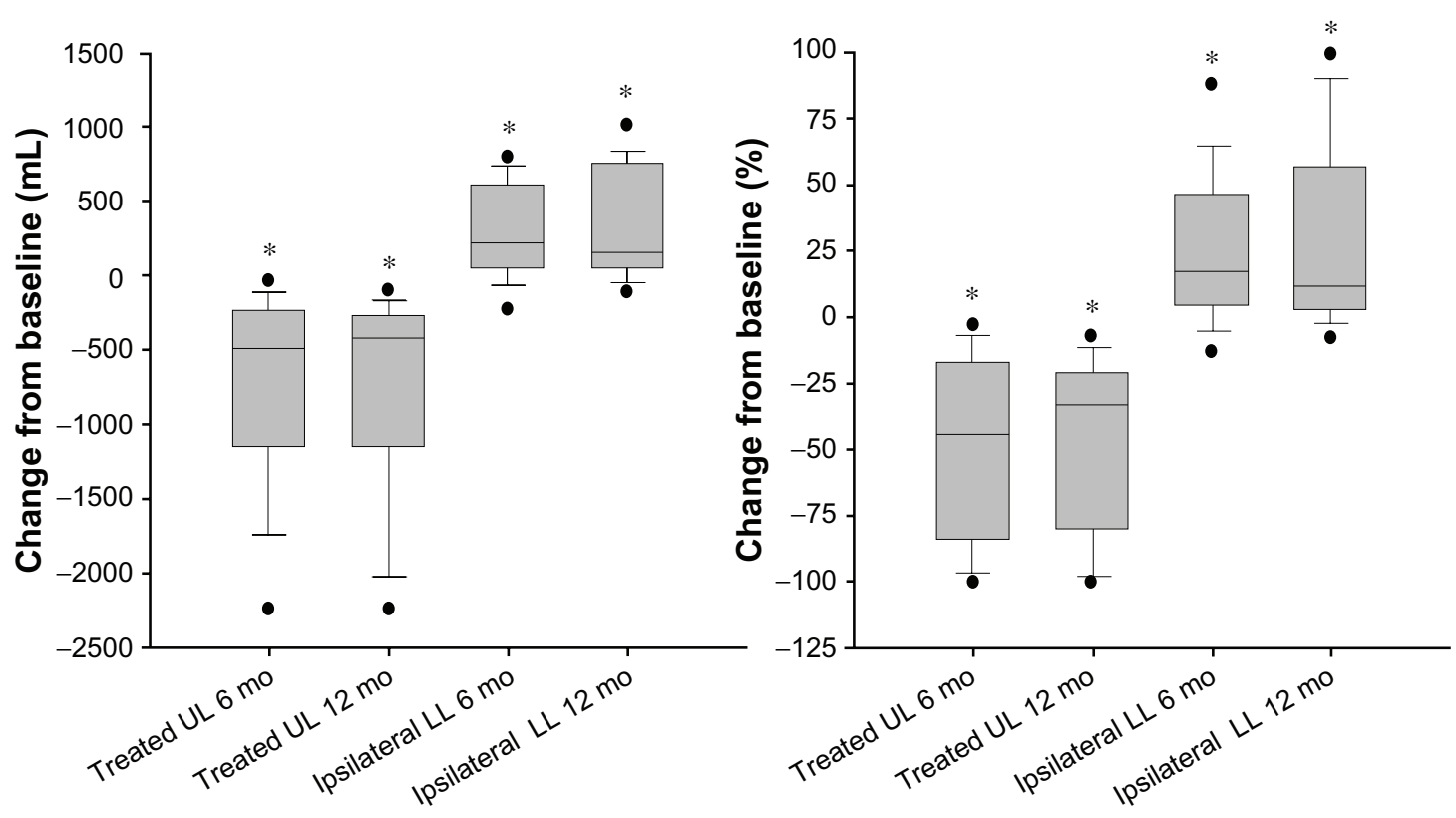

Figure I Change from baseline in treated upper lobe and ipsilateral lower lobe volumes 6 and I 2 months after InterVapor treatment.

Note: $* P<0.05$ vs baseline.

Abbreviations: UL, upper lobe; LL, lower lobe; mo, months. 

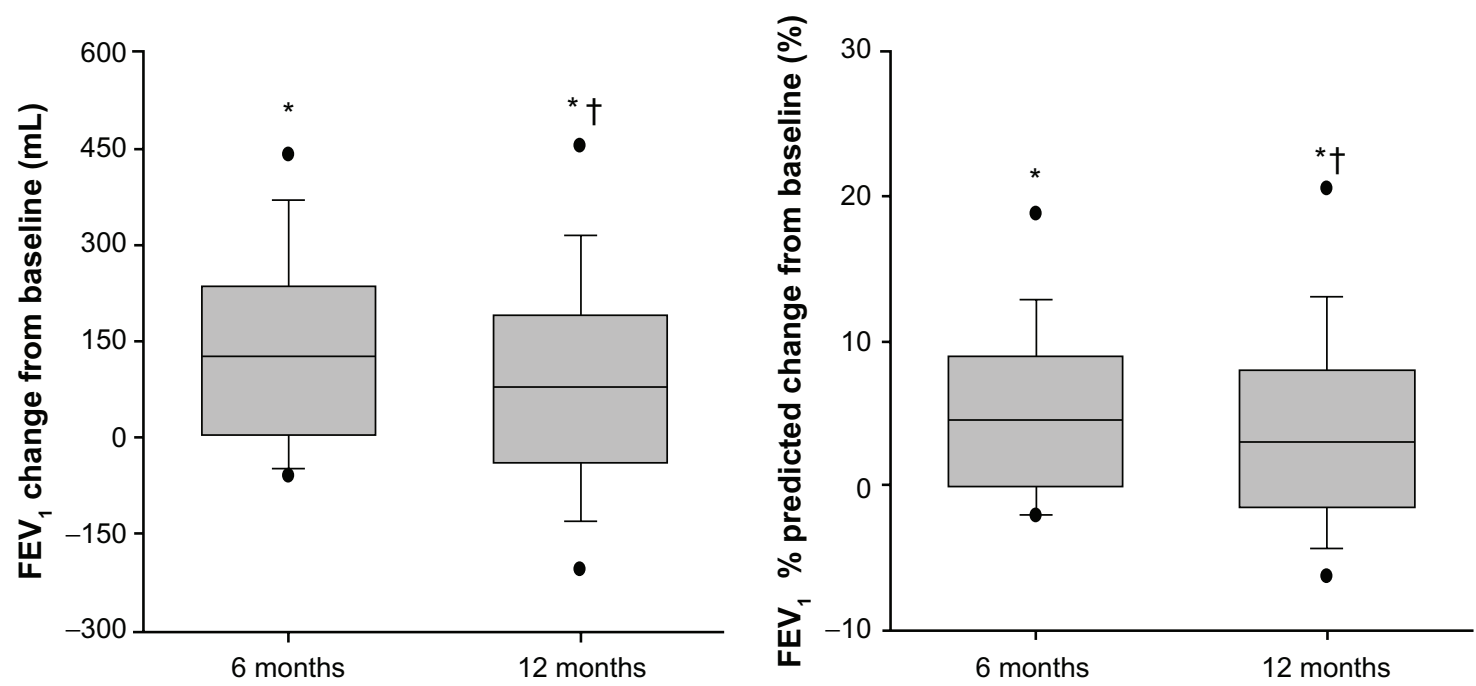

Figure 2 Change from baseline in $\mathrm{FEV}$ ( $\mathrm{mL}$ and \% predicted) 6 and 12 months after InterVapor treatment. Notes: $* P<0.05$ vs baseline; ${ }^{\dagger} P<0.0512$ months vs 6 months.

Abbreviation: FEV, forced expiratory volume in I second.

RV (\% predicted) being 228\% (48\%) versus 246\% (51\%) in $\mathrm{HI}<1.6$ and $>1.6$ groups, respectively. Efficacy was observed at 6 and 12 months in both subgroups with findings being overall higher in the higher HI group at 6 and 12 months (Table 5). The only between group differences associated with a nominal $P$ value $<0.05$ were for lobar volume reduction and RV at both 6 and 12 months.

\section{Safety}

For the 12-month follow-up, 39 serious adverse events were reported in 23 patients ( 22 events were respiratory). The most common serious adverse event was COPD exacerbation.
Events occurring within 6 months of treatment have been described previously. ${ }^{17}$ Ten serious adverse events occurred beyond 180 days in eight patients (COPD exacerbation $[\mathrm{n}=5]$, respiratory tract infection $[\mathrm{n}=1]$, investigation of diabetes [ $\mathrm{n}=1]$, acute dyspnea $[\mathrm{n}=1]$, cardiac insufficiency $[n=1]$, and right heart failure $[n=1])$. One patient died 67 days post-treatment secondary to end-stage lung disease. A second death occurred 350 days post-treatment due to complications following lobectomy performed for aspergillus infection of the untreated lung. The numbers of patients with serious adverse events over 12 months by subgroup were as follows: GOLD III $=9$, GOLD IV $=14$, HI $<1.6=10$,
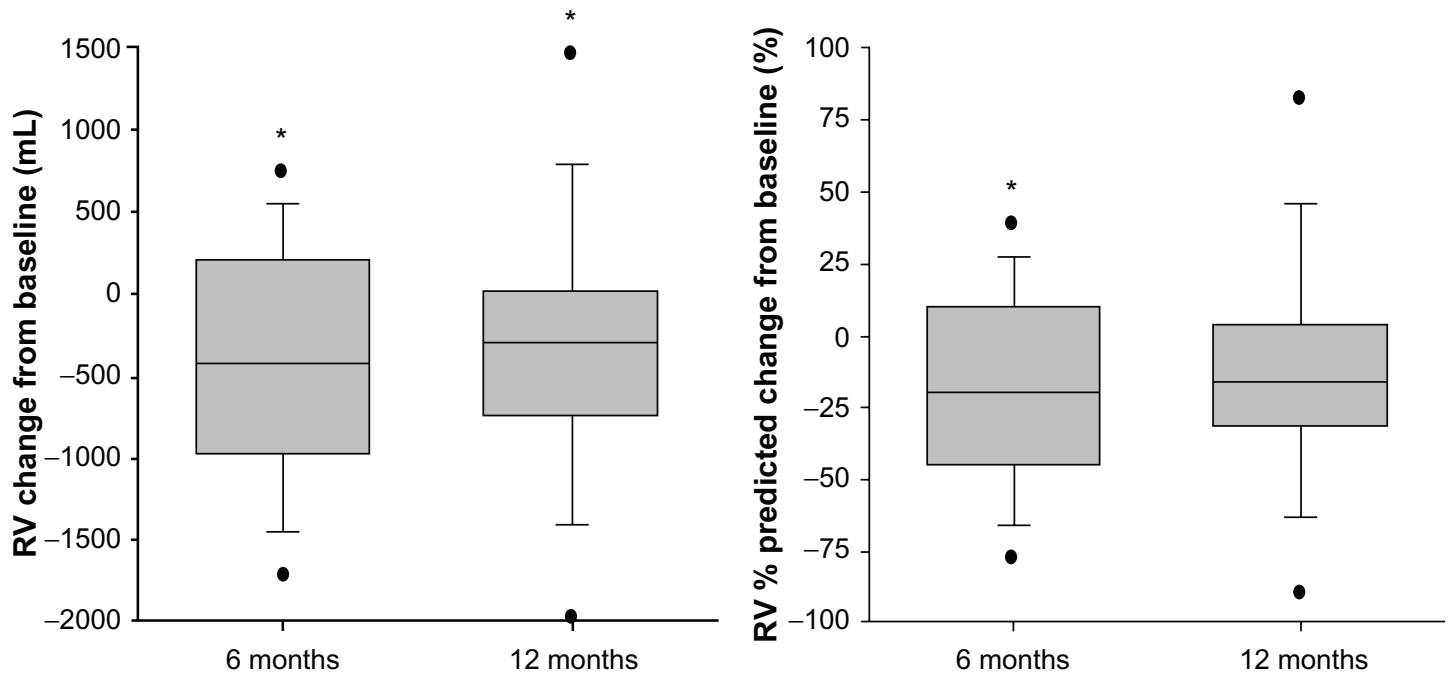

Figure 3 Change from baseline in RV ( $\mathrm{mL}$ and \% predicted) 6 and 12 months after InterVapor treatment.

Note: $* P<0.05$ vs baseline.

Abbreviation: RV, residual volume. 
Table 2 Change from baseline at 6 and 12 months in pulmonary function (absolute change and change in percent of predicted normal) following InterVapor

\begin{tabular}{|c|c|c|c|c|}
\hline & \multicolumn{2}{|c|}{$\Delta 6$ months $(n=40)$} & \multicolumn{2}{|c|}{$\Delta / 2$ months $(n=37)$} \\
\hline & Absolute & $\%$ predicted & Absolute & \% predicted \\
\hline $\mathrm{FVC}(\mathrm{mL})$ & $27 \mid(455)^{*}$ & $7.9(12.2)^{*}$ & $249(429)^{*}$ & $8.5(13.4)^{*}$ \\
\hline $\mathrm{FEV}_{1} / \mathrm{FVC}$ & $0.02(0.04)^{*}$ & NA & $0.00(0.05)^{\dagger}$ & NA \\
\hline $\operatorname{TLC}(\mathrm{mL})$ & $-220(445)^{*}$ & $-3(8)^{*}$ & $-65(532)^{\dagger}$ & $-0 . \mathrm{I}(\mathrm{II})^{\dagger}$ \\
\hline $\mathrm{FRC}(\mathrm{mL})$ & $-369(6 \mid 5)^{*}$ & $-12(20)^{*}$ & $-167(624)^{\dagger}$ & $-5(2 \mathrm{I})^{\dagger}$ \\
\hline $\mathrm{IC}(\mathrm{mL})$ & $149(403)^{*}$ & NA & I0I (495) & NA \\
\hline $\mathrm{RV} / \mathrm{TLC}$ & $-0.03(0.06)^{*}$ & NA & $-0.04(0.07)$ & NA \\
\hline $\mathrm{DLCO}(\mathrm{mL} / \mathrm{min} / \mathrm{mmHg})$ & $0.32(1.34)$ & I.5 (8.2) & $0.46(1.77)$ & I.2(8.3) \\
\hline
\end{tabular}

Notes: Values presented as mean (SD); $* P<0.05$ vs baseline; ${ }^{\dagger} P<0.0512$ months vs 6 months.

Abbreviations: FVC, forced vital capacity; $\mathrm{FEV}_{1}$, forced expiratory volume in I second; TLC, total lung capacity; FRC, functional residual capacity; IC, inspiratory capacity; $\mathrm{RV}$, residual volume; DLCO, diffusing capacity for carbon monoxide; NA, not applicable.

$\mathrm{HI}>1.6=13$. During the first 30 days, the corresponding numbers of patients were $5,6,4$, and 7 .

\section{Discussion}

Several endoscopic options for inducing lung volume reduction have been developed for patients with severe and very severe emphysema. ${ }^{7-17}$ InterVapor is one such technique and delivers thermal energy through heated water vapor directly to the airways via a bronchoscope ${ }^{15-17}$ At 6 months, a single-arm international clinical study of 44 patients demonstrated that InterVapor resulted in $48 \%$ lobar volume reduction, which was associated with reduced hyperinflation and improvements in airflow, dyspnea, exercise tolerance, and health-related quality of life. ${ }^{17}$ Additional data from a 12-month follow-up visit indicates that improvements relative to baseline continued to be observed, with the magnitude of benefit less than that documented at 6 months. However, HRCT lobar volume reduction was stable over 12 months ( $46 \%$ at 12 months).

For patients with GOLD stage III and IV disease, improvements from baseline at 6 months were similar, while improvements at 12 months were more robust in GOLD stage IV patients. One explanation could be a ceiling effect where there is more "room" to improve in GOLD stage IV patients; however, this should have been apparent at 6 months. Another explanation may be related to

Table 3 SGRQ total score and domains at baseline and change from baseline at 6 and 12 months following InterVapor

\begin{tabular}{lllll}
\hline & 6 months & $\Delta$ score & I2 months & $\Delta$ score \\
\hline Symptoms & $43.2(24.0)$ & $-11.9(21.8)^{*}$ & $48.5(25.4)$ & $-6.4(25.4)$ \\
Activity & $64.4(20.4)$ & $-14.7(17.7)^{*}$ & $68.3(19.6)$ & $-10.3(16.9)^{* . \dagger}$ \\
Impact & $32.1(21.3)$ & $-14.0(16.1)^{*}$ & $33.0(21.1)$ & $-12.7(13.2)^{*}$ \\
Total & $43.8(19.5)$ & $-14.0(15.1)^{*}$ & $46.2(19.2)$ & $-11.0(14.0)^{*}$ \\
\hline
\end{tabular}

Notes: Values presented as mean (SD); ${ }^{*} P=0.05$ vs baseline; ${ }^{\dagger} P<0.0512$ months vs 6 months.

Abbreviation: SGRQ, St George's Respiratory Questionnaire. differential contribution of small airways disease (obstructive bronchiolitis) versus emphysema, which might lead to GOLD stage III patients having more regions of the lung that can have compensatory hyperinflation. There may be more rapid equilibrium or changes in regional lung volumes when there is less severe disease relative to lungs with more uniformly severe disease. In terms of patient reported outcomes and exercise tolerance, it may be that improvements in ventilatory mechanics have a higher impact in GOLD stage IV patients relative to other factors such as nutritional, musculoskeletal, and cardiovascular disease. Other potential, but less likely, explanations include differences in regional perfusion and a more rapid $\mathrm{FEV}_{1}$ decline in GOLD stage III versus stage IV patients. The above explanations are speculative and the caveat remains that the overall sample size within the two subgroups is relatively small and differences may simply be random.

Regarding subgroup analyses, any differences in efficacy must be balanced by safety considerations. As part of the mechanism of action, patients receiving InterVapor may develop a temporary increase in symptoms with an infiltrate in the treated lobe. However, the current dataset indicates that there does not appear to be longer term safety issues. Any adverse events related to treatment should always be considered in the context of COPD morbidity and mortality, particularly in GOLD stage IV patients. ${ }^{22,23}$

The other major subgroup was based on the degree of heterogeneity. The calculations determining heterogeneity within the current trial are more objective than that used in the National Emphysema Treatment Trial, which utilized visual judgment with relatively broad categories. ${ }^{3,4}$ Despite differences in methodology, the current findings that suggest larger responses with higher degrees of heterogeneity are consistent with the National Emphysema Treatment Trial results. ${ }^{4}$ Furthermore, the findings are consistent with 
Table 4 Changes in efficacy outcomes at 6 and 12 months according to GOLD stage III and GOLD stage IV disease severity

\begin{tabular}{|c|c|c|c|}
\hline & Baseline & $\Delta 6$ months & $\Delta / 2$ months \\
\hline \multicolumn{4}{|c|}{ GOLD stage IV $(n=22)$} \\
\hline $\begin{array}{l}\text { Lobar volume } \\
(\mathrm{mL})\end{array}$ & $1474(484)$ & $-690(692)^{*}$ & $-772(734)^{*}$ \\
\hline $\mathrm{FEV}_{1}(\mathrm{~mL})$ & $715.9(202.5)$ & I $42.0(\mid 82.9)^{*}$ & $108.9(182.25)^{*}$ \\
\hline $\mathrm{RV}(\mathrm{mL})$ & $4970.5(1033.7)$ & $-302.0(780.4)$ & $-335.6(908.3)$ \\
\hline $\begin{array}{l}\text { SGRQ total } \\
\text { (units) }\end{array}$ & 63.7 (II.9) & $-17.4(16.9)^{*}$ & $-12.7(15.0)^{*}$ \\
\hline 6MWD (m) & $270.6(65.8)$ & $48.7(78.5)^{*}$ & $25.6(72.1)^{\dagger}$ \\
\hline $\mathrm{mMRC}$ score & $3.0(0.7)$ & $-0.8(1.1)^{*}$ & $-0.9(0.8)^{*}$ \\
\hline \multicolumn{4}{|c|}{ GOLD stage III $(n=22)$} \\
\hline $\begin{array}{l}\text { Lobar volume } \\
(\mathrm{mL})\end{array}$ & $1503(488)$ & $-743(565)^{*}$ & $-735(601)^{*}$ \\
\hline $\mathrm{FEV}_{1}(\mathrm{~mL})$ & $1005.5(2 \mid 5.2)$ & I $39.5(\text { ( } 52.4)^{*}$ & $64.7(167.5)^{\dagger}$ \\
\hline $\mathrm{RV}(\mathrm{mL})$ & $4989.6(1114.0)$ & $-510.0(643.4)^{*}$ & $-270.0(641.3)$ \\
\hline $\begin{array}{l}\text { SGRQ total } \\
\text { (units) }\end{array}$ & $54.1(14.5)$ & $-10.6(12.7)^{*}$ & $-9.4(13.1)^{*}$ \\
\hline 6MWD (m) & $329.3(77.5)$ & $44.4(55.4)^{*}$ & $10.9(54.5)$ \\
\hline $\mathrm{mMRC}$ score & $2.8(0.8)$ & $-1.0(1.1)^{*}$ & $-0.7(\mathrm{I} . \mathrm{I})^{*}$ \\
\hline
\end{tabular}

Notes: Values presented as mean (SD); $* P=0.05$ vs baseline; ${ }^{+P}<0.0512$ months vs 6 months.

Abbreviations: $\mathrm{FEV}$, forced expiratory volume in I second; RV, residual volume; SGRQ, St George's Respiratory Questionnaire; 6MWD, 6-minute walk distance; mMRC, modified Medical Research Council dyspnea scale.

efficacy observations from a large controlled trial with endobronchial valves. ${ }^{12}$ The explanation for the apparent association with upper lobe predominant heterogeneity has not been adequately explained; however, heterogeneity is another phenotype that assists in assessment of patient candidacy for endoscopic lung volume reduction.

Table 5 Changes in efficacy outcomes at 6 and 12 months according to $\mathrm{HI}>\mathrm{I} .6$ and $\mathrm{HI}<1.6$

\begin{tabular}{|c|c|c|c|}
\hline & Baseline & $\Delta 6$ months & $\Delta / 2$ months \\
\hline \multicolumn{4}{|l|}{$\mathrm{HI}>\mathrm{I} .6(\mathrm{n}=22)$} \\
\hline Lobar volume $(\mathrm{mL})$ & $1630(580)$ & $-963(704)^{\dagger}$ & $-1078(753)^{\dagger}$ \\
\hline $\mathrm{FEV}_{1}(\mathrm{~mL})$ & 870 (249) & $183(197)^{\dagger}$ & $139(200)^{*}$ \\
\hline $\mathrm{RV}(\mathrm{mL})$ & $5053(923)$ & $-654(738)^{*}$ & $-571(837)^{*}$ \\
\hline SGRQ total (units) & $55.9(12.7)$ & $-12.5(17.0)^{*}$ & $-13.2(13.6)^{\dagger}$ \\
\hline 6MWD (m) & $297.0(93.6)$ & $48.4(55.7)^{*}$ & $25.0(59.8)$ \\
\hline mMRC score & $2.9(0.8)$ & $-1.2(1.1)^{\dagger}$ & $-1.0(1.2)$ \\
\hline \multicolumn{4}{|l|}{$\mathrm{HI}<\mathrm{I} .6(\mathrm{n}=22)$} \\
\hline Lobar volume $(\mathrm{mL})$ & 1347 (309) & $-484(43 I)$ & $-426(304)$ \\
\hline $\mathrm{FEV}_{1}(\mathrm{~mL})$ & $852(262)$ & $102(125)^{*}$ & $36(|3|)^{\ddagger}$ \\
\hline $\mathrm{RV}(\mathrm{mL})$ & 4907 (I 202) & $-182(627)$ & $-63(645)$ \\
\hline SGRQ total (units) & $61.8(14.9)$ & $-15.3(13.5)$ & $-9.0(14.4)^{*}$ \\
\hline 6MWD (m) & $302.9(58.0)$ & $44.8(77.3)^{*}$ & $12.3(68.3)^{\ddagger}$ \\
\hline mMRC score & $2.9(0.7)$ & $-0.7(1.0)^{*}$ & $-0.7(0.7)$ \\
\hline
\end{tabular}

Notes: Values presented as mean (SD); $* P=0.05$ vs baseline; $\dagger P<0.0512$ months vs 6 months.

Abbreviations: $\mathrm{HI}$, heterogeneity index; $\mathrm{FEV}$, forced expiratory volume in I second; RV, residual volume; SGRQ, St George's Respiratory Questionnaire; 6MWD, 6-minute walk distance; mMRC, modified Medical Research Council dyspnea scale.
A limitation in the current approach was the somewhat arbitrary HI threshold of 1.6, which was only based on dichotomizing patients using the median value, which might differ if the trial was repeated.

Although clear benefits are observed following InterVapor, a numerical difference in the magnitude of effectiveness was observed from 6 to 12 months. The histopathologic response with inflammation followed by contraction fibrosis is presumably stable over the 12-month observation period. HRCT data from the current study shows stability of lobar volume reduction in the treated lobe between 6 and 12 months. Clinical factors related to COPD are therefore the most likely explanations. A loss of lung function, health-related quality of life, and exercise tolerance is expected over time. ${ }^{24,25} \mathrm{~A}$ recent randomized, double-blind, sham-controlled study of airway bypass in 315 patients with advanced emphysema demonstrated an annual loss of $\mathrm{FEV}_{1}$ in the control population of approximately $40 \mathrm{~mL}$ ( $6 \%$ decline), which is consistent with other studies. ${ }^{24-26}$ Assuming that a control population would have behaved similarly, a between-group difference (InterVapor vs control) of $86+40=126 \mathrm{~mL}$ would be anticipated at 12 months. Other possible factors include compensatory hyperinflation of the contralateral lung, exacerbations, and comorbidities. Additionally, as no visit was scheduled between 6 and 12 months, adherence to prescribed respiratory medications may have changed that could have led to worsening lung function. These hypotheses could be addressed with a control group. Nevertheless, all of the hypotheses would only contribute to underestimating the magnitude of benefit and not overstate the current observations. It is of interest to note that the mean improvement in BODE score remained above 1 at 12 months suggesting that a survival benefit might be anticipated. ${ }^{21}$ A possible survival benefit has been described in a case series of patients who experienced atelectasis following lung volume reduction with endobronchial valves, which would be consistent with the above BODE data. ${ }^{27}$

Several limitations of the current study are acknowledged. The trial involves 44 patients and therefore has limited power to explore subgroups, yet the consistency of the results with all endpoints directionally positive, and with most of the efficacy endpoints associated with nominal $P$ values less than 0.05 , indicate the findings are not random. The other major limitation is the open nature design of the trial. However, an objective measure such as lobar volume reduction measured by HRCT would not change in a control group. 
In summary, the current data provide longer term clinically relevant information about the effect of unilateral InterVapor in patients with severe and very severe predominantly upper lobe emphysema. Positive outcomes relative to baseline included lobar volume reduction along with improvements in physiology, dyspnea, and health-related quality of life. The magnitude of benefit was higher at 6 months compared to 12 months; however, serious adverse events diminished over time suggesting no long term safety concerns. The 12 month data substantiate the need for clinical trials in emphysema to follow patients beyond 6 months. Subgroup analyses identified patient populations that may have larger benefits that extend to the 12 month final observation period. Those subgroups include patients with more advanced disease (GOLD stage IV) and those with higher heterogeneity. Further studies including a control group would assist in confirming observations related to subgroups.

\section{Acknowledgments}

We wish to gratefully acknowledge the statistical support from William Anderson and the editorial support of Stephanie Tuck. We also wish to thank the following people who supported the trial: S Asadi, C Bolger, A Carle, Dr C Chambers, Dr R Eberhardt, Dr D Gompelmann, Dr I Firlinger, Dr L Fu, C Hollis, L Holsworth, Dr A Kempa, Dr U Leibers, L Murphy, B Reiche, K Sprenger, Dr G Westall, and Prof T Williams.

\section{Disclosure}

This study was sponsored by the manufacturer of InterVapor, Uptake Medical Corp (Tustin, CA).

\section{References}

1. Brantigan OC, Mueller E. Surgical treatment of pulmonary emphysema. Am Surg. 1957;23(9):789-804.

2. Cooper JD, Trulock EP, Triantafillou AN, et al. Bilateral pneumectomy (volume reduction) for chronic obstructive pulmonary disease. J Thorac Cardiovasc Surg. 1995;109(1):106-116.

3. The National Emphysema Treatment Trial Research Group. Rationale and design of the National Emphysema Treatment Trial: A prospective randomized trial to lung volume reduction surgery. Chest. 1999;116(6):1750-1761.

4. The National Emphysema Treatment Trial Research Group. A randomized trial comparing lung-volume-reduction surgery with medical therapy for severed emphysema. N Engl J Med. 2003;348(21): 2059-2073.

5. Naunheim KS, Wood DE, Mohsenifar Z, et al. National Emphysema Treatment Trial Research Group. Long-term follow-up of patients receiving lung-volume-reduction surgery versus medical therapy for severe emphysema by the National Emphysema Treatment Trial Research Group. Ann Thorac Surg. 2006;82:431-443.

6. Criner GJ, Cordova F, Sterberg AL, Martinez FJ. The NETT: Part II lessons learned about lung volume reduction surgery. Am J Resp Crit Care Med. 2011;184(8):881-893.
7. Snell GI, Holsworth L, Borrill ZL, et al. The potential for bronchoscopic lung volume reduction using bronchial prostheses: a pilot study. Chest. 2003;124(3):1073-1080.

8. Toma TP, Hopkinson NS, Hillier J, et al. Bronchoscopic volume reduction with valve implants in patients with severe emphysema. Lancet. 2003;361(9361):931-933.

9. Hopkinson NS, Toma TP, Hansell DM, et al. Effect of bronchoscopic lung volume reduction on dynamic hyperinflation and exercise in emphysema. Am J Respir Crit Care Med. 2005;171(5):453-460.

10. Venuta F, de Giacomo T, Rendina EA, et al. Bronchoscopic lungvolume reduction with one-way valves in patients with heterogeneous emphysema. Ann Thorac Surg. 2005;79(2):411-416.

11. Wan IY, Toma TP, Geddes DM, et al. Bronchoscopic lung volume reduction for end-stage emphysema: report on the first 98 patients. Chest. 2006;129(3):518-526.

12. Sciurba FC, Ernst A, Herth FJF, et al. A randomized study of endobronchial valves for advanced emphysema. $N$ Eng J Med. 2010;363(13): 1233-1244.

13. Herth FJF, Gompelmann D, Stanzel F, et al. Treatment of advanced emphysema with emphysematous lung sealant $\left(\right.$ AeriSeal $\left.{ }^{\mathbb{}}\right)$. Respiration. 2011;82(1):36-45.

14. Springmeyer S, Bolliger CT, Waddell TK, Gonzalez X, Wood DE. Treatment of heterogeneous emphysema using the Spiration IBV valves. Thorac Surg Clin. 2009;19:247-253.

15. Emery MJ, Eveland RL, Eveland KB, Couetil LL, Hildebrandt J, Swenson ER. Lung volume reduction by bronchoscopic administration of steam. Am J Respir Crit Care Med. 2010;182(10):1282-1291.

16. Snell GI, Hopkins P, Westall G, Holsworth L, Carle A, Williams TJ. A feasibility and safety study of bronchoscopic thermal vapor ablation: a novel emphysema therapy. Ann Thorac Surg. 2009;88(6):1993-1998.

17. Snell G, Herth FJ, Hopkins P, et al. Bronchoscopic thermal vapour ablation therapy in the management of heterogeneous emphysema. Eur Respir J. 2012;39(6):1326-1333.

18. ATS statement: guidelines for the six-minute walk test. Am J Resp Crit Care Med. 2002;166(1):111-117.

19. Jones PW, Quirk FH, Baveystock CM, Littlejohns P. A selfcomplete measure of health status for chronic airflow limitation: the St George's Respiratory Questionnaire. Am Rev Respir Dis. 1992;145(6): 1321-1327.

20. Bestall JC, Paul EA, Garrod R, Garnham R, Jones PW, Wedzicha JA. Usefulness of the Medical Research Council (MRC) dyspnoea scale as a measure of disability in patients with chronic obstructive pulmonary disease. Thorax. 1999;54(7):581-586.

21. Celli B, Cote CG, Marin JM, et al. The body-mass index, airflow obstruction, dyspnea, and exercise capacity index in chronic obstructive pulmonary disease. $N$ Engl J Med. 2004;350(10):1005-1012.

22. Global strategy for the diagnosis, management, and prevention of chronic obstructive pulmonary disease. Executive summary. December 2011 Update. Global Initiative for Chronic Obstructive Lung Disease. Available from: http://www.goldcopd.com/Guidelineitem. asp?11=2\&12=1\&intId=989. Accessed February 2, 2011.

23. The World Health Report 2000. Statistical Annex. Geneva: World Health Organization; 2000. Available from: http://www.who.int/whr/2000/en/ whr00_annex_en.pdf. Accessed February 2, 2011.

24. Tashkin DP, Celli B, Senn S, et al. for the UPLIFT investigators. A four year trial of tiotropium in patients with chronic obstructive pulmonary disease. New Engl J Med. 2008;359(15):1543-1554.

25. Vestbo J, Edwards LD, Scanlon PD, et al. Changes in forced expiratory volume in 1 second over time in COPD. New Eng J Med. 2011;365(13): 1184-1192.

26. Shah PL, Slebos D-J, Cardoso PFG, et al. Bronchoscopic lung-volume reduction with Exhale airway stents for emphysema (EASE trial): randomised, sham-controlled, multicenter trial. Lancet. 2011;378(9795): $997-1005$.

27. Hopkinson NS, Kemp SV, Toma TP, et al. Atelectasis and survival after bronchoscopic lung volume reduction for COPD. Eur Respir J. 2011;37(6):1346-1351. 
International Journal of COPD

\section{Publish your work in this journal}

The International Journal of COPD is an international, peer-reviewed journal of therapeutics and pharmacology focusing on concise rapid reporting of clinical studies and reviews in COPD. Special focus is given to the pathophysiological processes underlying the disease, intervention programs, patient focused education, and self management protocols.

This journal is indexed on PubMed Central, MedLine and CAS. The manuscript management system is completely online and includes a very quick and fair peer-review system, which is all easy to use. Visit $\mathrm{http}: / /$ www.dovepress.com/testimonials.php to read real quotes from published authors.

Submit your manuscript here: http://www.dovepress.com/international-journal-of-copd-journal 